\title{
Realizing the value of knowledge resources and capabilities: An empirical study
}

\begin{abstract}
Purpose - Drawing upon the resource-based view of the firm, this paper develops and empirically validates a model, which examines the relationships between technical KM infrastructure (TKMI), social KM infrastructure (SKMI), and competitive advantage provided by KM (CAPKM). The authors argue that KM process capabilities account for the direct effects of TKMI and SKMI on CAPKM.

Design/methodology/approach - We employed PLS-SEM to empirically test the hypotheses using a sample of 251 firms from an emerging economy. The results were then confirmed using the bias-corrected bootstrap procedure. We also conducted two robustness checks including: (a) examining a competing moderation model, (b) and performing fuzzy-set qualitative comparative analysis (fsQCA), a set-theoretic method that examines how causal conditions combine into all possible configurations of binary states to explain the desired outcome.

Findings - The findings show that TKMI and SKMI have positive effects on CAPKM. In addition, KM process capabilities mediate the direct effects of TKMI and SKMI on CAPKM.

Originality/value - This paper complements and advances prior research in several ways. First, the paper develops a conceptual model that depicts the interrelationships between TKMI, SKMI, KM process capabilities, and CAPKM. Second, this paper suggests the critical role of the "action" component (i.e. KM process capabilities) that capitalizes on the KM resources in the creation of CAPKM.
\end{abstract}

Keywords technical knowledge management, social knowledge management, knowledge management process capabilities, competitive advantage provided by knowledge management. Paper type Research paper 


\section{Introduction}

The knowledge management (KM) literature makes it clear that KM outcomes associated with competitive advantage are based on three separate but highly complementary factors. These factors include technical KM infrastructure (TKMI), social KM infrastructure (SKMI), and KM process capabilities. TKMI refer to technological resources that enable and support KM processes in an organisation. Leonard-Barton (1995) and Grant (1996) propose that the technological dimensions that are part of effective $\mathrm{KM}$ include business intelligence, collaboration, distributed learning, knowledge discovery, knowledge mapping, opportunity generation, and security. Recent research on TKMI (Mills and Smith, 2011), however recommend collaboration, distributed learning, and knowledge mapping as the three major dimensions of TKMI. SKMI refer to the role of KM infrastructure elements from social perspectives that stimulate KM activities in an organisation. A broad range of these factors have been identified in the literature such as organisational structure, organisational culture, leadership, people, and KM strategy (e.g. Gold, Maholtra and Segars, 2001; Lee and Choi, 2003; Migdadi 2005; Zheng, Yang, and McLean, 2010). KM process capabilities refer to the ability of firms in "acquiring knowledge, converting it into a useful form, applying or using it, and protecting it" (Gold et al., 2001, p. 190). Various perspectives of KM processes identified in the literature include discover/ generate/ create/ acquire, capture, codify, coordinate/collaborate, accumulate/integrate, transfer, store, share, access, represent, use/ apply, and deploy/exploit (e.g., Mageswari, Sivasubramanian, and Dath, 2017; Pentland, 1995; Wu and Chen, 2014; Zaim, Tatoglu, and Zaim, 2007). However, there is growing consensus in the knowledge management literature that KM process capabilities is a composite construct that captures a firm's ability in 
four facets: knowledge acquisition, conversion, application, and protection (Gold et al., 2001; Mills and Smith, 2011; Granados et al., 2017).

Despite the theoretical and practical importance of KM resources (i.e. TKMI and SKMI) and $\mathrm{KM}$ process capabilities, the KM literature is limited in terms of two aspects. First, prior research has largely focused on narrow conceptions of KM resources and capabilities and examined them in isolation focusing on either KM resources or KM capabilities (Gold et al., 2001; Ashrafi and Mueller, 2015; Andreeva and Kianto, 2012; Byrd and Turner, 2001; Chuang, 2004; Lee and Choi, 2003). While resources may serve as the basic unit for analysing how firms achieve competitive advantage, firms' competitive advantage result from their ability to integrate resources that complement one another to create organisational capabilities (Bharadwaj, 2000). Indeed, the RBV advocates that "resources are static, ... and the potential value of resources is realized by way of resource deployment competencies, which are how firms capitalize on resources to effect superior performance" (Ngo and O'Cass, 2012, p. 863). As such, in the current study we propose that KM resources and capabilities may not contribute to firm performance in isolation but the performance impact of $\mathrm{KM}$ resources and capabilities rests on their complementarity.

Second, the extant literature seems to agree conceptually that KM resources (e.g. TKMI and SKMI) should contribute to a firm's competitive advantage. However, empirical results provide only mixed support. For example, Powell and Dent-Micallef (1997) and Chuang (2004) find that TKMI is not significantly related to competitive advantage, but others find that TKMI and SKMI are positively related to competitive advantage (e.g. Andreeva and Kianto, 2012; Byrd and Turner, 2001). As such, RBV researchers have raised doubts about the unquestioning focus that firms may place on their resources in that "strategic resources only have potential value, and 
that realizing this potential requires alignment with other important organizational elements" (Ketchen et al., 2007, p. 962).

Third, as most extant research on KM infrastructure, processes and capabilities has been conducted in Western developed countries such as USA (Gold et al., 2001; Zheng, 2005), Australia (Migdadi, 2005), and newly industrialised Asian economies such as Taiwan (Chuang, 2004), Hong Kong (Khalifa, Lam and Lee, 2001; Khalifa and Liu, 2003), and Korea (Choi and Lee, 2002, 2003; Lee and Choi, 2003), the role of these factors in other contexts, such as transitional economies (e.g. Vietnam), is still unclear. Transitional economies experience unprecedented changes in their economic, social, and legal system as a consequence of their transition from central systems to market systems (Child and Tse, 2001). Yet, given the limited research in this area, how $\mathrm{KM}$ resources and $\mathrm{KM}$ process capabilities work together toward achieving superior competitive advantage still remains largely unknown (Gimenez and Ricon, 2003). To examine the interrelationship among KM resources and KM process capabilities and their impact on competitive advantage, transitional economies (e.g. Vietnam) offer a unique opportunity to test the existing KM theories and to build new ones.

Our paper is structured as follows. First, by reviewing the extant literature, we establish the theoretical relationship between TKMI, SKMI, KM process capabilities, and competitive advantage, and present the related hypotheses. We then introduce research methodology, analytical procedure, and report findings. Finally, we close by discussing the results, and highlighting implications for managerial practice and conclusion. 


\section{Theoretical background and model development}

The resource-based view is a long-standing theory, which has its foundations in strategic management. The resource-based view asserts that firms attain competitive advantage based on unique resources that remain valuable, rare, inimitable and non-substitutable by other resources (Barney, 1991; Conner, 1991; Schulze, 1992). The fundamental assumption underlying the resource-based view is that resources are heterogeneously dispersed across different firms and the differences between these firms based on the resources remain steady over time (Barney, 1991). Scholarly research on the resource-based view tends to define and classify resources broadly to include assets, knowledge, capabilities, and firm processes (Bharadwaj, 2000). However, Grant (1991) distinguishes between resources and capabilities by classifying resources into tangible, intangible, and human-based resources. While tangible resources refer to financial capital and assets such as equipment, plants, and raw materials, intangible resources include firm reputation, brand image, as well as product quality. Human-based resources include technical know-how and other knowledge assets such as organisational culture and employee training.

While resources remain the basis for which competitive advantage may be achieved, competitive advantage can be created by firms based on their ability to integrate resources that complement one another to create organisational capabilities (Bharadwaj, 2000). Therefore, organisational capabilities involve firms' ability to integrate and utilise valuable resources which complement one another (Amit and Schoemaker, 1993; Russo and Fouts, 1997; Schendel, 1994). From this perspective of resources and capabilities, KM remains central to the identification of what resources are, and how their integration and utilisation as complement create organisational capabilities that can lead to competitive advantage (Hedlund and Nonaka, 1993). 
The pivotal role of $\mathrm{KM}$ in facilitating competitive advantage from resources and capabilities include KM infrastructure and KM processes (Gold et al., 2001). While KM infrastructure can be technical or social (Lee and Choi, 2003), social KM infrastructural resources may include organisational structure, organisational culture, and people resources (Chuang, 2004; Lee and Choi, 2003). Gold et al (2001) consider KM infrastructure to include organisational structure, organisational culture, and technology resources. The conflicting considerations of the organisational structure, organisational culture, and people and technical resources obfuscate the understanding of how these resources clearly relate to competitive advantage. This obfuscation suggests that although a consideration of how social and technical KM infrastructural resources affect competitive advantage as distinct constructs remains compelling, the modus operandi through which they contribute to competitive advantage cannot be discounted.

The extant literature on the role of KM process capability is equivocal and inconclusive. While some studies consider KM process capability as an independent variable (Gold et al., 2001), others theorize this construct as a mediator (Tanriverdi, 2005), and moderator (Chuang, 2004), which makes it imperative to further clarify the role of KM process capability in the linkage between KM resources and competitive advantage. In the current study, we position KM process capability as the mediator in the relationship between KM resources and competitive advantage. We propose that $\mathrm{KM}$ process capability is the salient mechanism in transforming TKMI and SKMI into competitive advantage. Understanding how TKMI and SKMI are transformed into competitive advantage through KM process capabilities may shed light on salience of this mechanism. Our position is in line with an RBV framework in that Ketchen et al (2007, p. 962) suggest that resources "allow the firm to do a better job of taking strategic actions 
[e.g. capabilities] ... that capitalize on the resources [to create] a competitive advantage". We build our conceptual model based on this important argument (see Figure 1).

Insert Figure I about here

\subsection{Knowledge management and competitive advantage provided by KM (CAPKM)}

Competitive advantage is derived from the assets and resources that constitute a firm (Barney, 1991; Peteraf, 1993; Dierickx \& Cool, 1989). However, while many executives concern themselves with acquisition, accumulation and aggregation of assets as a way to create competitive advantage, many forget the power that knowledge and information provide in the marketplace. In this respect, it has been shown information is a clear source of competitive advantage (Porter \& Millar, 1985; Altinay, Saunders, \& Wang, 2014). Despite that, competitive advantage is a complex, multi-dimensional construct that can be construed in many ways depending on context. Prior research has examined a construct namely competitive advantage provided by information systems (CAPIS) "to measure the contribution of all the IS to competitive advantage in an organization" (Byrd \& Turner, 2001a, p. 22). In line with this stream of research, we examine competitive advantage provided by knowledge management (CAPKM). In particular, we draw upon that of Byrd and Turner (2001b), who posit competitive advantage includes four dimensions: innovativeness, market position, mass customization and inimitability. For knowledge and information to provide competitive advantage, it is within reason that a firm's knowledge management capabilities must also link with these four dimensions. Because of this, we look to research by Chuang (2004) as one of the key relevant 
studies in which a four-item measure was developed to assess CAPKM based on the dimensions outlined by Byrd and Turner (2001b). The findings presented by Chuang (2004) indicate a clear link between a firm's knowledge management and competitive advantage in the marketplace.

\subsection{TKMI capabilities and CAPKM}

Building upon the resource-based view, information technology (IT) alone does not generate sustainable competitive advantage owing to possible imitation by competitors (Ross, Beath and Goodhue, 1996; Powell and Dent-Micallef, 1997). To be strategically competitive, businesses must use technologies to leverage or exploit other firm-specific, intangible resources such as organisational leadership, culture, human resource, and business processes (Clemons and Row, 1991; Henderson and Venkatraman, 1993). Using technology to leverage other resources in the organisation is deeply rooted in the firm's ability to integrate IT resources that complement one another to create organisational capabilities that lead to competitive advantage (Grant, 1991). For instance, prior research finds that the integration of IT practices of KM into organisational activities and systems has a direct relationship with firm competitive advantage (Andreeva and Kianto, 2012). Additionally, if such IT practices involve flexible IT infrastructure, it makes the organisation more responsive and agile, and enhances the firm's capabilities to create competitive advantage (Byrd and Turner, 2001). The relationship between IT infrastructure and competitive advantage becomes even stronger when the firm assembles and develops high level IT personnel knowledge and skill (Byrd, Lewis and Turner, 2005). Accordingly, there is a reasonable justification to believe that TKMI will have a direct impact on firm competitive advantage provided by KM. Thus, we hypothesize that:

H1: TKMI has a positive effect on CAPKM. 


\subsection{SKMI capabilities and CAPKM}

According to Lee and Choi (2003), organisations with strong social knowledge management resources, including culture, structure, and people, are able to integrate the knowledge management and business planning processes more effectively, to develop reliable and innovation applications that support the business needs of the firm faster than competition, and to predict future business needs of the firm and innovate valuable new product features before competitors. Gold et al. (2001) also posit that the social infrastructure of culture, structure and people typically evolve over long periods of time through the sustainability of organisational operations. While each of these resources is difficult to acquire and complex to imitate (Barney, 1991), firms that achieve competitive advantage through KM have also learned to combine their resources effectively to create overall social infrastructure capabilities (Grant, 1991). According to the resource-based view, when firms possess valuable resources which become difficult for other firms to imitate, it offers firms the capabilities to create a sustainable competitive advantage (Barney, 1991; Chuang, 2004). Thus, we hypothesize that: H2: SKMI has a positive effect on CAPKM.

\subsection{KM process capabilities and CAPKM}

Gold et al., (2001) conceptualize KM process capabilities as a composite construct that has four dimensions including knowledge acquisition, conversion, application, and protection. Knowledge acquisition process involves an organization's ability to accumulate relevant knowledge for its operational activities by recognizing and obtaining such knowledge from both internal and external sources. Knowledge conversion, however, refers to the organization's ability to sort, structure, synchronize and allocate knowledge according to common themes to reduce redundancy, increase 
consistency, and boost efficiency in terms of usefulness. Knowledge application involves activities that enable the organization to utilize knowledge effectively in creating value. Knowledge protection refers to the activities that enable the organization to guard against illegal or inappropriate use of knowledge. The impact of KM processes on organizational performance outcomes remains wellestablished in the literature. In particular, prior research finds a positive relationship between KM processes, either as a multi-dimensional construct (e.g., Gold et al., 2001; Zaim et al., 2007) or unidimensional variables (e.g., Mills and Trevor, 2011), and organizational performance. The current state of the literature is lacking because no detailed explanations are offered as to how and why KM process capabilities matter in the relationship between KM resources and competitive advantage.

The contribution of knowledge management processes in gaining and sustaining competitive advantage has been conceptually discussed in the extant literature. Chakravarthy, McEvily, Doz and Rau (2005, p.305) posit that while 'the characteristics of knowledge are primarily valuable for defending existing advantages, the processes it uses to accumulate and leverage knowledge have greater implications for creating new sources of advantage'. Each of the three knowledge management activities plays a distinctive role in providing firms a competitive advantage: knowledge leverage is necessary for growth, knowledge accumulation to ensure that this growth is profitable, and knowledge protection to sustain this profitable growth. Based on the dynamic capability based approach, Nielsen (2006) also demonstrates a connection between knowledge management processes with the three key dynamic capabilities of development, (re)combination, and use of knowledge, enabling firms to achieve and sustain a competitive advantage in a dynamic marketplace (Eisenhardt and Martin, 2000; Hamel and Prahalad, 1996; Powell and Snellman, 2004; Verona and Ravasi, 2003; Winter, 2003). 
For instance, Tanriverdi (2005) found that the infrastructure, strategy making processes, human resource management processes, and vendor management processes which constitute the IT relatedness of the firm's business units, enhance KM capabilities across the units of the firm and, in turn, lead to superior firm performance. Moreover, Zheng, Yang and McLean (2010) find that KM effectiveness mediate between organisational structure, organisational culture, and organisational strategy on one side and measures associated with firm's competitive advantage on the other side. Such findings on KM capabilities bear ample testimony of the potential mediation role of KM process capabilities between social and TKMI and firm competitive advantage.

From the perspective of technology assimilation, IT must be infused and diffused into business processes to enhance organisational performance (Cooper and Zmud, 1990; Fichman and Kemerer, 1997; Khalifa and Liu, 2003). In the context of KM, therefore, the technical infrastructure capabilities should become the enabler of process capabilities to improve its indirect effect on a firm's competitive advantage (Nguyen and Neck, 2008). The role of how IT enhances KM processes has been broadly discussed in the KM literature (e.g. Alavi and Leidner, 2001; Alavi and Tiwana, 2005; Davenport and Prusak, 1998; Khalifa and Liu, 2003; Sher and Lee, 2004; Zack, 1999). Moreover, the ability of such an enhancement of KM processes by IT infrastructure and the impact of KM process capabilities on competitive advantage has been established in the literature (e.g., Chuang, 2004; Gold et al., 2001; Tanriverdi, 2005). Accordingly, we hypothesise that:

H3: KM process capabilities mediates the relationship between TKMI and CAPKM.

Gold et al. (2001) argue that social capital theory stresses the importance of infrastructure elements, enabling maximisation of social capital by providing a mechanism for social 
interaction of individuals as the basis for KM. Knowledge, or intellectual capital, is created through the process of exchange and combination that occur within this social network of an organisation (Nahapiet and Ghoshal, 1998). Closely tied to the theory of social capital, the knowledge-based theory of the firm also highlights the effective means of coordinating individuals' activities within the firm and integrating their knowledge (Grant, 1996; Lopez, 2005). This is where the role of organisational infrastructure elements comes into play to effectively manage the firm's knowledge (Gold et al., 2001).

The ability of social knowledge infrastructure capabilities to stimulate and improve KM process capabilities has been supported by many researchers such as Zander and Kogut (1995), Szulanski (1996), Hansen (1999), and Appleyard (1996). Additionally, the impact of the improved KM process capabilities by SKMI capabilities on firm competitive advantage has been established in the literature by findings in various studies such as Chuang (2004), Gold et al., (2001), Tanriverdi (2005) and Zheng et al. (2010). Accordingly, a reasonable justification exists for us to believe that KM process capabilities will mediate the relationship between SKMI capabilities and firm competitive advantage. Therefore, we hypothesise that:

H4: KM process capabilities mediates the relationship between SKMI and CAPKM.

\section{Research methodology}

\subsection{Samples and procedure}

To test our model, we collected data from firms in Vietnam. The Vietnamese economy has shown remarkable performance with its steady growth over the last 10 years (Meschi et al., 2017). As an emerging economy, Vietnam offers a rich setting to examine how knowledge resources and knowledge capabilities are capitalized into competitive advantage. We prepared 
the measurement instrument initially in English and then translated into Vietnamese. We checked it for accuracy by using back translation process (Brislin et al., 1973). We used a sample of 1000 firms selected randomly from a mailing list of the 2000 Business Directory issued by the Vietnamese Chamber of Commerce and Industry. The sampled firms were located in HoChiMinh City and Hanoi, the two biggest cities of Vietnam. These firms span diverse ownership types (e.g. state-owned, private, international joint venture, foreign wholly owned). With the help of a national research firm, we selected a senior manager (e.g. managing director, marketing manager, financial manager, $R \& D$ manager) in each firm in the sampled list as the key informant. A questionnaire packet, included cover letter, stamped return envelope, and questionnaire was sent to 1000 senior managers via mail, followed up by two reminders to increase the response rate. In the cover letter, we informed the respondents of the academic purpose of the research project, the confidentiality of their responses, and promised them a summary report in return for their participation.

We applied pairwise deletion method of missing cases and received 251 useable responses, producing an acceptable response rate of $25.1 \%$ and satisfying the minimum ratio of 5:1 between the number of cases and parameters in the study (Hair et al., 2006; Kline, 1998). Table I shows the demographic profile of respondents. In total, 68.92 percent of the respondents were male and 31.08 percent were female, which reflects the male dominance in senior management positions of Vietnamese companies. Most respondents were in the ages of 31-to-40 (43.03 percent), followed by 41-to-50 (23.11 percent), less than 30 years of age ( 21.91 percent), and older than the age of 50 (11.95 percent). This pattern may imply a tendency of encouraging new blood in the management teams of Vietnamese companies. Most respondents had tenure ranging from 3-5 years (31.08 percent) and 6-10 years (31.08), followed by 11-20 years (21.12 
percent), 1-2 years (10.36 percent), and longer than 20 years (6.36 percent). All respondents held at least a bachelor degree of which $27.89 \%$ were managing directors, $25.10 \%$ were from marketing, $15.14 \%$ were financial managers, $10.36 \%$ were from $\mathrm{R} \& \mathrm{D}, 8.37 \%$ were from production, $5.98 \%$ from HR, $3.97 \%$ from project management, and $3.19 \%$ from IT. The respondents' company profiles were analyzed on their size, types of ownership, and basic categories of industry. The largest proportion of participating firms were local private-owned (58.17 percent), employing less than 300 employees (81.27 percent) and operated in the service industry (62.15 percent). Only a small percentage was international joint-venture and foreign wholly owned enterprises (8.37 and 7.1. percent, respectively). The result of cross-tabulation analysis shows that a majority of the state-owned companies were of larger size and operated in the manufacturing sector while the service industry consisted of smaller-sized and private-owned companies.

Insert Table I in here

\subsection{Measures of constructs}

We employed previously developed and well-established scales to measure the focal constructs of the proposed theoretical model. All multi-item constructs were measured with a seven-point Likert scale (1-strongly disagree; 7-strongly agree) as shown in Table II. We measured TKMI as a formative first-order construct with a four-item scale, borrowed from Mills and Smith (2011). We asked managers to respond to the use of technology in operational activities throughout the firms. Following Gold et al. (2001), McDermot and O’Dell (2001) and Lee and Choi (2003), we measured SKMI as a formative first-order, reflective second-order construct with a sixteen-item 
scale, reflecting three dimensions - structural infrastructure (seven items), cultural infrastructure (four items), and people infrastructure (five items). On the basis of Gold et al. (2001) and Inkpen (1996), we measured KM process capabilities as a formative first-order, reflective second-order construct with a twenty-six-item scale, reflecting four dimensions - acquisition process (six items), conversion process (six items), application process (seven items), and protection process (seven items).

Competitive advantage provided by knowledge management (CAPKM) was captured by a four-item scale based on the work of Byrd and Turner (2001b) and Chuang (2004). Four single items associated with innovativeness, market position, mass customization, and difficult to duplicate. Despite its drawbacks (see Hair et al., 2010), the use of single-item indicators in structural equation models in marketing research is not uncommon (Petrescu, 2013). Prior research recommends the use of single-item indicators when multiple items cannot be obtained. Innovativeness is "internally-focused and competitive-advantage seeking, since it encourages openness to new ideas and cultivates internally-based capabilities to adopt new ideas, processes, or products successfully" (O'Cass and Ngo, 2007, p. 870). Relative market position is also of paramount importance for competitive advantage. Firms can erect strong barriers to entry for their rivals by building and deploying knowledge into favourable market position (Hult et al., 2006). Mass customization is another important dimension of competitive advantage. Indeed, firms competing in rapidly changing business environments should be able to use and integrate KM system for recognizing the customers' preference timely and design the products and services accordingly (Gu, Jitpaipoon, \& Yang, 2017; Kotha, 1995). Finally, building KM systems that are rare, valuable, non-substitutable, and imperfectly imitable is essential for 
competitive advantage. Such KM system make it difficult and expensive for rivals to duplicate (Byrd and Turner, 2001b).

Insert Table II \& III about here

\section{Analysis and results}

\subsection{Common method bias}

In the current study, we used cross-sectional data to test the proposed theoretical model using a single-informant approach. As such, common method bias effects may lead to spurious relationships among the variables (Podsakoff, MacKenzie, Lee and Podsakoff, 2003). Therefore, we applied the following statistical remedies to test for common method bias. We conducted the marker variable technique (Lindell and Whitney, 2001), using gender as a marker variable. The average absolute correlation between gender and all other constructs in our model was .05 ( $\mathrm{rm})$. The average difference between the correlations among all constructs in the model after partialing out the effect of $\mathrm{rm}$ was 0.02 , and the intercorrelations between all the constructs in our model remained significant after partialing out the effect of rm. This suggests that "the results cannot be accounted for by common method variance" (Lindell and Whitney, 2001, p. 118). We also examined the correlations between TKMI, SKMI, KM process capabilities, and competitive advantage, and calculated their corresponding Variance Inflation Factor (VIF) values to ensure no multicollinearity problem. We found no evidence of multicollinearity because the VIF scores ranged between 1.20 and 3.08, which were far below the critical value of 5 (Hair, Sarstedt, Hopkins and Kuppelwieser, 2014). 


\subsection{Hypothesis testing}

We conducted the hypothesis testing through a three-stage process. First, we employed partial least squares analysis (PLS) with SmartPLS 3.0 software (Ringle, Wende and Becker, 2015) to test the proposed hypotheses. PLS-SEM is a non-parametric approach, which "draws on composites formed from the indicators and applies a series of ordinary least squares regressions to estimate partial model structures with the objective of minimizing the error terms ... of the endogenous constructs" (Hair et al., 2017, p. 4). Second, we supplemented this analysis with the PROCESS macro, a bootstrapping technique recommended by Preacher and Hayes (2008). PROCESS is a computational tool available for SPSS and SAS that simplifies the implementation of mediation, moderation, and conditional process analysis with observed variables (Hayes, 2013; Hayes et al., 2017). PROCESS has become especially popular in business and management as evidenced by its appearance in prior research (e.g. Cameron and Stone, 2010; Van Den Hooff et al., 2012). Third, we checked the robustness of the main findings by conducting fuzzy-set qualitative comparative analysis (fsQCA). fsQCA is a novel methodology, which is based on the idea that causal relations are frequently better understood in terms of set-theoretic relations rather than correlations (Ragin, 2008; Fiss, 2011).

\subsubsection{PLS-SEM}

As shown in Table IV, TKMI positively influences competitive advantage (Model $1, \beta=0.14$, $\mathrm{t}=2.15$ ), thus hypothesis 1 is supported. In the same vein, SKMI positively influences competitive advantage (Model $1, \beta=0.62, \mathrm{t}=13.12$ ), thus hypothesis 2 is supported. In hypothesis 3, we predicted KM process capabilities mediates the relationship between TKMI and competitive advantage. As shown in Model 2, TKMI positively influences KM process 
capabilities (Model 2, $\beta=0.26$, t-value $=4.63$ ), which in turn positively influences competitive advantage (Model 2, $\beta=0.64, \mathrm{t}$-value $=7.60$ ). We compared Model 1 and Model 2 and found that the positive effect of TKMI on competitive advantage in Model 1 became insignificant in Model $2(\beta=0.04$, t-value $=0.80)$. By calculating the variance accounted for $(V A F)$, we sought to determine the size of the indirect effect in relation to the total effect, which was 0.81 . That is, $81 \%$ of the total effect of TKMI on competitive advantage was indirect, so KM process capabilities fully mediates the effect of TKMI on competitive advantage, in support of Hypothesis 3.

In hypothesis 4 , we predicted $\mathrm{KM}$ process capabilities mediates the relationship between SKMI and competitive advantage. As shown in Model 2, SKMI positively influences KM process capabilities (Model 2, $\beta=0.68, \mathrm{t}$-value $=13.8$ ), which in turn positively influences competitive advantage (Model 2, $\beta=0.64$, t-value $=7.60)$. We compared Model 1 and Model 2 and found that the positive effect of TKMI on competitive advantage in Model 1 became weaker in Model $2(\beta=0.19, \mathrm{t}$-value $=2.54)$. By calculating the variance accounted for $(\mathrm{VAF})$, we sought to determine the size of the indirect effect in relation to the total effect, which was 0.70 . That is, $70 \%$ of the total effect of SKMI on competitive advantage was indirect, so KM process capabilities partially mediates the effect of SKMI on competitive advantage, in support of Hypothesis 4. We also controlled for firm size and ownership type which had no significant relationships with competitive advantage.

For our robustness check, we examined a competing model with KM process capabilities as a moderator between TKMI and competitive advantage, and between SKMI and competitive advantage, rather than as a mediator. However, the moderating effects were insignificant $(\mathrm{p}=0.01, \mathrm{p}=0.02$ respectively). This provides greater evidence for the mediation model as 
opposed to the moderating model. In addition, we also found that the interaction between SKMI and TKMI had no significant effect on competitive advantage.

\subsubsection{PROCESS macro}

In order to provide further support for the mediating effect of KM process capabilities, we followed Preacher and Hayes' (2008) mediation analysis procedure. In particular, we used the PROCESS macro Model 4 (Hayes, 2013), which provides bootstrap estimates with bias corrected confidence intervals of the indirect effects. The mediation effects were significant (hypothesis $3:$ TKMI $\rightarrow$ KM process capabilities $\rightarrow$ competitive advantage, $b=0.30, \mathrm{CI}=0.22-$ 0.41; and hypothesis $4: \mathrm{SKMI} \rightarrow \mathrm{KM}$ process capabilities $\rightarrow$ competitive advantage, $\mathrm{b}=0.56$, $\mathrm{CI}=0.40-0.77)$.

\section{Insert Table IV in here}

\subsubsection{Fuzzy-set qualitative comparative analysis}

We reanalyzed the hypotheses using fuzzy-set qualitative comparative analysis (fsQCA) in order to enhance the robustness of our finding. fsQCA is complementary to structural equation modeling that examines pre-determined relationships (Woodsie, 2013). In this study, we employed a three-stage approach recommended by Fiss (2011) and Ragin (2008) to conduct fsQCA. First, we transformed the measures of constructs in the model into fuzzy-set membership scores. Specifically, we calibrated all the independent and dependent variables of our study, which involves classifying values of each variable into full membership (covering 95\% of the 
data values), cross-over (covering $50 \%$ of the data values) and full non-membership (covering $5 \%$ of the data values). Second, we constructed and refined the truth table that presents all possible configurations of causal conditions of the desired outcome by selecting a frequency threshold and a consistency threshold. Frequency refers to the minimum number of cases required for a configuration to be considered (Fiss, 2011). We set the frequency threshold at 30 to ensure that the configurations selected captured at least $80 \%$ of cases. Consistency refers to the degree to which the cases sharing a given configuration of attributes exhibit the desired outcome (Fiss, 2011). We set the consistency threshold at 0.87 which is above the minimum consistency threshold of 0.80 (Ragin, 2008). Third, we used the Quine-McClusky algorithm to logically reduce the truth table rows to simplified configurations. The fsQCA results in Table V show that TKMI, SKMI, and KM process capabilities are all significantly associated with competitive advantage (raw coverage $=0.67$; consistency $=0.87$ ). This indicates that none of the conditions is sufficient to increase competitive advantage; yet the combination of TKMI, SKMI, and $\mathrm{KM}$ process capabilities is required to achieve competitive advantage. Thus, we provide greater robustness to our findings by illustrating that TKMI, SKMI, and KM process capabilities are important elements of a complex causal combination in explaining variance in competitive advantage.

Insert Table $\mathrm{V}$ in here 


\section{Discussion}

This paper set out to examine the role of technical (TKMI) and social (SKMI) knowledge management infrastructure within a firm and their effect on competitive advantage. Specifically, the primary objective was to determine whether TKMI and SKMI are determinants of a firm's knowledge management process capabilities (KMPC) and whether KMPC mediates the relationship between TKMI, SKMI, and competitive advantage. The results support current research and confirm that both TKMI and SKMI have direct effects on competitive advantage. In addition, the findings extend existing theory and show that KMPC acts as a mechanism between both TKMI and SKMI and a firm's competitive advantage.

The acquisition, management and application of knowledge within a firm can have a powerful influence on an organisation's competitive advantage. To conduct such activities, firms must employ an assortment of technical infrastructure and social capital in order to achieve strategic outcomes. However, for these technical and social assets to fully achieve their desired aim, a range of supporting processes must be in place to bring them to life.

In this instance, the technological KM infrastructure provides the network capabilities that allow organisational members to locate and make use of knowledge resources. At the same time, the SKMI provides the organisational culture where employees and managers understand theirs and each other's roles in knowledge management. Together, the technological and social infrastructures create a suite of process capabilities that formalise knowledge management within the organisation. Ultimately, it is these KMPCs that determine a firm's competitive advantage.

Such a system eventually challenges typical resource-based views of competitive advantage (e.g. Barney, 1991; Conner, 1991) where organisational resources are considered to positively influence competitive advantage because they are unique, not substitutable and 
relatively finite within a given market. However, many CIOs are likely to attest that technical infrastructure is readily substitutable and can easily be copied by other firms. That is not to say the value of technical infrastructure is in any way diminished. In fact, the current research provides compelling evidence that technical resources provide the foundation for competitive advantage, which is consistent with theory put forward by Amit and Schoemaker (1993) and Russo and Fouts (1997).

Along with this, the current study demonstrates and confirms the theory of Bharadwaj (2000) that integration of resources is critical for developing organisational capabilities. There is a large body of research (e.g. Andreeva and Kianto, 2012; Byrd and Turner, 2001; Chuang, 2004; Granados et al., 2017; Grant, 1991) in which resources are defined in a number of ways, including technical, social, cultural, or tangible/intangible. However, there is a distinct lack of cohesion in how these resources are combined to create competitive advantage. In real-world, live scenarios this can be highly problematic for two closely related reasons. First, TKMI investment not only has the potential to demand large capital outlays but typically requires long lead times from planning to deployment. Second, even the best TKMI has the potential to be under-utilised or lie dormant if the requisite social and cultural infrastructure is not deployed to make use of the technology. As such, if organisations, project teams and managers do not adequately plan the integration of technical and social resources, any investment in TKMI is likely to be costly and have limited influence on sustainable competitive advantage (Gold et al., 2001). Despite that, simply possessing TKMI and SKMI resources is not the proverbial silver bullet that will ensure ongoing competitive advantage. Instead, it is the way these resources combine to form a range of process capabilities that will ultimately deliver lasting competitive advantage. 
The knowledge management processes in place within an organisation are critical determinants in both developing and sustaining new sources of competitive advantage (Chakravarthy et al., 2005). However, previous research has typically focused on the effects of TKMI and SKMI on competitive advantage in isolation. Rather, the current study has looked at how TKMI and SKMI simultaneously influence competitive advantage. As such, it appears to be the first evidence that KMPC is the mechanism that influences the relationship between TKMI and SKMI as independent variables and competitive advantage as the primary dependent variable. From a theoretical perspective, the findings provide empirical support for the propositions forwarded by Nguyen and Neck (2008) that TKMI (and, by association SKMI) should be the 'enabler' of process capabilities, which then provide an indirect route to competitive advantage. From a managerial perspective, such evidence provides a mandate for internal policy development covering each step in the knowledge management process.

Building on this, the current research has demonstrated that managers need to put in place programs that will allow the organisation to develop its knowledge management process capabilities. More specifically, programs that link with the four dimensions of knowledge management outlined by Gold et al. (2001) - acquisition, conversion, application and protection - must be managerial priorities to build process capabilities. This is because a firm's knowledge management process capabilities allow the technical and social knowledge management infrastructure to come to life. Ultimately, this is how ongoing competitive advantage is developed and maintained.

To acquire knowledge, firms need to engage in two key activities. The first is benchmarking of their own knowledge management practices against industry and global standards. The second is to develop a culture of collaboration, where employees are willing to 
collaborate and share knowledge internally, as well as externally within a firm's network of partners (Gold et al., 2001). This collaboration then allows the aggregation and accumulation of knowledge that can be harvested for strategic and operational purposes.

Being able to harvest knowledge contained within an organisation is dependent on established conversion mechanisms. In this respect, managers must look to formalise a set of rules or directives, whereby individuals can easily tap into existing knowledge or have access to other employees in procedures that mandate group decision-making.

For effective use and application of knowledge, guidelines and policies must then be developed that situate organisational knowledge not as a static asset, but as a constantly evolving, dynamic open-source entity. While the application of knowledge has some clear overlap with conversion, organisational culture is sure to have a major impact on how readily members share - or search for - information. Because of this, there is likely to be an ongoing tension between the need for immediate, short-term gains obtained through formal procedures to share information and longer-term gains that emanate from a culture of knowledge sharing. As a result, managers must look to develop an organisational culture where knowledge sharing becomes accepted, automatic and habitual (He \& Wei, 2009). This way, managers can ensure formal knowledge management processes are complemented by informal, socially-led knowledge sharing (Granados et al., 2017)

The final piece in the puzzle that is a firm's process capabilities is knowledge protection. The protection of knowledge is a complex, difficult task for any organisation. No doubt, firms can use patents or copyright to protect knowledge assets. However, this is an area for future research, where protection of knowledge needs to be examined away from the typical frameworks that position legal or technical IT provisions as the only available powers. 
Apart from these managerial necessities, the current research has redefined the antecedents of competitive advantage as independent and mediator variables, thereby challenging what has been found in previous research. Namely, that knowledge management is presented as a single construct when considering its influence on organizational performance outcomes (e.g., Zack, McKeen, and Singh, 2009). By contrast, the current study demonstrates that although performance implications of KM depend on KM practices, such $\mathrm{KM}$ practices include TKMI and SKMI forming the basis of KM activities, where KMPC operates as a key facilitator of organizational performance outcomes. Additionally, the findings on the antecedents of competitive advantage offer significant theoretical implications for existing models that consider single dimensions of multi-dimensional constructs as either independent or mediator variables for organizational performance outcomes (e.g., Mageswari et al., 2017; Tseng, 2016; Tseng, 2010). What is more, the findings of this study provide evidence that knowledge conversion and organizational culture operate both independently (as mediator and independent variable respectively) and jointly (where each variable forms part of a multi-dimensional construct) as determinants of organizational performance. Specifically, where organizational culture contributes to SKMI and knowledge conversion contributes to KMPC.

The findings from the current study provide evidence for KMPC as a mediator between KM infrastructure and competitive advantage. When viewed against previous research where organizational performance outcomes are seen as directly dependent on KM infrastructure and KMPC (e.g., Mills and Smith, 2011; Zaim et al., 2007), the current study appears to extend existing theory. For example, although Mills and Smith (2011) found no significant direct effect of technology infrastructure and organizational culture on organizational performance, future research may look at the role of KMPC as a mediator in the model. Additionally, the mediation 
role of KMPC implies that although organizational performance directly depends on both KM infrastructure and KM processes as found by Zaim et al., (2007), there is also a significant indirect relationship between $\mathrm{KM}$ infrastructure and organizational performance through the mediation of KMPC.

Current theory from existing KM research (e.g. Wu \& Chen, 2014) suggests KMPC has no direct relationship with organizational performance outcomes unless the relationship is mediated by business process capability. However, the present study challenges assertions by Wu and Chen (2014), by demonstrating a significant, direct link between KMPC and competitive advantage. Thus, although business process capabilities may intervene in the relationship between KMPC and organizational performance, such an intervention does not invalidate a direct relationship between KMPC and organizational performance. Future research may be required to further test this relationship.

In addition to the theoretical and managerial contributions outlined, the current study has answered the call by Gimenez and Ricon (2003) for additional research investigating the role of KM in less-developed countries. For this study, Vietnam was used as the referent country, given it has been identified as a developing nation (United Nations, 2016). Previous research has examined individual countries in order to develop and test generalizable theory (Nguyen et al., 2003; Vu et al., 2016; Zhou, 2017), so the use of a single country as the context for the current study is in keeping with extant literature. That said, this means there is still substantial scope for future research to ensure the findings hold in other developing nations, particularly those that lie outside Asia.

Less developed countries, such as Vietnam, are likely to have less TKMI resources than more developed nations. Likewise, there is the potential for less-developed nations to have lower 
levels of SKMI resources as the existing human capital within the labour force is also still in a developmental phase. By extension, it is plausible this would also lead to less formal KM processes given KM may still be in its infancy. Regardless, the findings from the current study indicate existing theory developed in more advanced nations is applicable in less-developed countries and vice-versa. This is an exciting development, both theoretically and managerially. It indicates the absolute values of each variable are not as relevant as the relationships between them. As a result, irrespective of the actual expenditure on TKMI and SKMI, if managers can put in place processes to harness the power within the organisation's KM resources, on-going sustainable competitive advantage is a viable, obtainable outcome.

Apart from the organisational or economic advantages that may be derived from knowledge management, there may also be a range of positive social implications. Based on the premise that 'knowledge is power', it may be that knowledge management and process capabilities can be used at the regional, national or transnational levels to effect change that will have positive social, environmental and economic outcomes (Laszlo \& Laszlo, 2002). For example, knowledge management and information sharing have been shown to significantly influence the management of poverty and disability (Buettgen et al., 2012). Likewise, the ability for stakeholders to share knowledge and engage in an informed discourse was a key driver in Iceland's response to the global financial crisis of the 2000s (Duffy et al., 2017). If such macrolevel knowledge management practices continue to evolve, it is possible we will see the continual development of 'knowledge cities' (Ergazakis et al., 2004). This would be particularly beneficial for developing nations, such as Vietnam, where the development of knowledge and KM abilities could result in increased investment from international firms. 
Despite the significant theoretical and managerial implications of the present study, it has several limitations which also offer avenues for future research. First, because the present study utilizes a cross-sectional survey, the relationships between variables are associative rather than predictive. Thus, future research may adopt a longitudinal approach to examine the present model. Second, KMPC as a mediator in the present study's model offers a novel and important contribution to scholarly research in KM. However, the data for testing the model emanated from a developing country (i.e., Vietnam). Therefore, future research will be required to test the model in more advanced countries in order to compare the extent of consistency or variation in the model across contexts. Third, the present study's model examines the outcome of KM infrastructure and KMPC on organizational performance with respect to competitive advantage. However, other outcomes of KM infrastructure and KMPC on organizational performance can be financial performance, employee engagement/attrition, innovation among others (e.g., Tseng, 2010, 2016; Mageswari et al., 2017; Zack et al., 2009). Future research may examine the impact of SKMI, TKMI, and KMPC on KM outcomes other than competitive advantage. Finally, the current research sought to identify the relationships between the different knowledge management dimensions. However, how these dimensions interact in different strategic contexts is clearly an area for future research. While people and organisational culture are key ingredients for successful knowledge management initiatives (Rubenstein-Montano et. al., 2001), an organization's strategic context will influence selection of the most appropriate initiatives that link with overall corporate objectives (Zack, 1999). What is more, the current research involved firms from a range of industries. In future, it may also be beneficial to examine the differences and commonalities in knowledge management processes that exist between firms that have similar strategic contexts but operate in different industries. 


\section{Conclusion}

In the modern business environment, knowledge is a highly valuable commodity that can offer significant competitive advantage. This paper has examined the relationships between Technical KM infrastructure, Social KM infrastructure, KM process capabilities and competitive advantage. Moving away from the typical resource-based view of competitive advantage provides an objective picture of knowledge and its movement through the KM network from acquisition, through to conversion. In turn, viewing the route knowledge takes to influence competitive advantage sheds light, not just on the mechanisms at work within the network, but on the managerial responsibilities for ensuring KM processes are in place and clearly linked to the requisite organisational outcomes. The findings from the current research indicate senior management cannot assume expenditure on technical $\mathrm{KM}$ infrastructure alone will result in increased competitive advantage. Instead, Chief Knowledge Officers must ensure KM infrastructure is matched with KM process capabilities that will facilitate the acquisition, conversion, application and protection of knowledge. 
Figure 1. Theoretical framework

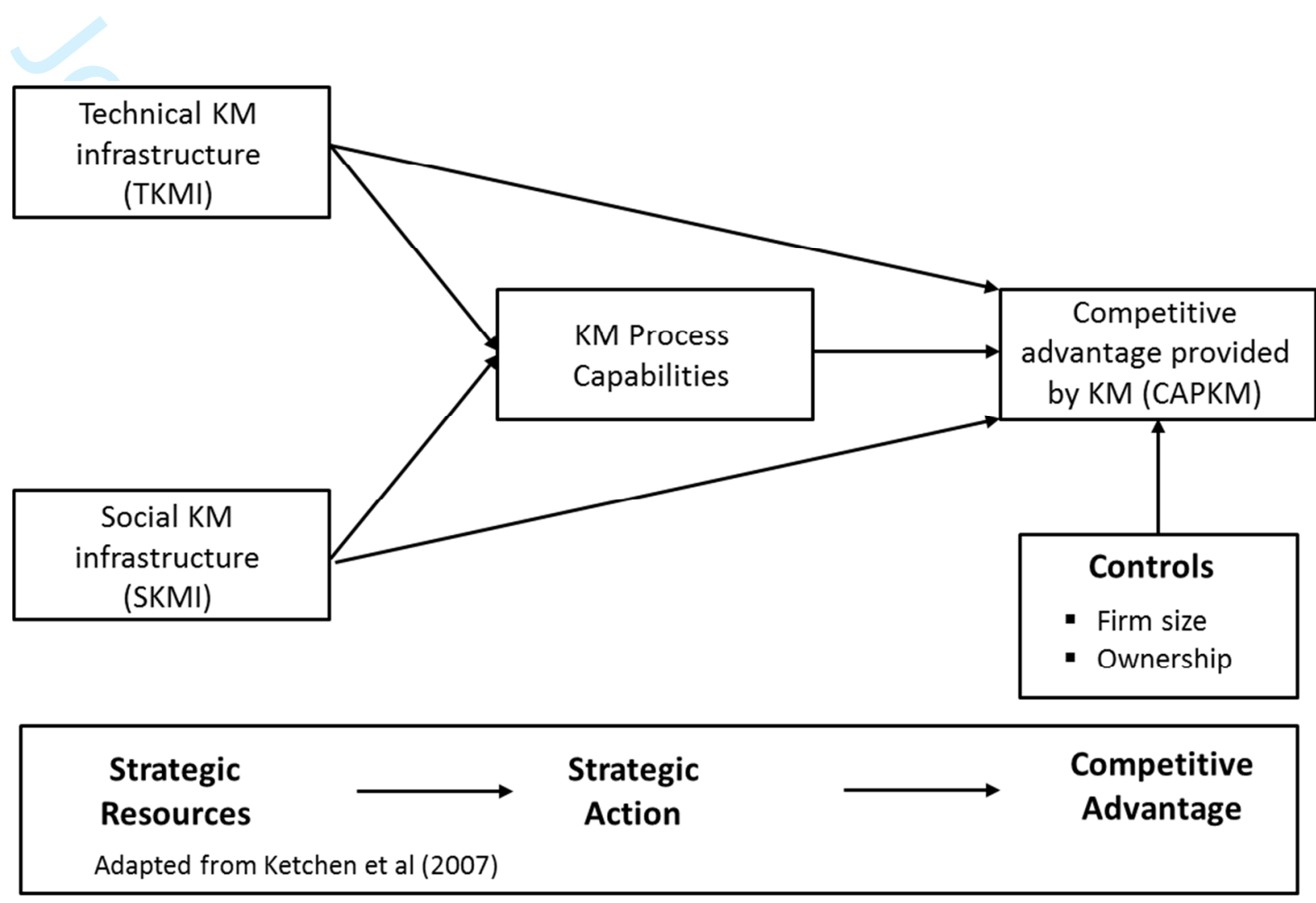


Table I Demographics of the respondents

\begin{tabular}{lrclrr}
\hline Demographics & $\begin{array}{r}\text { Frequency } \\
(n=251)\end{array}$ & $\%$ & Demographics & $\begin{array}{r}\text { Frequency } \\
(n=251)\end{array}$ & $\%$ \\
\hline Gender & & & Tenure & & \\
Male & 173 & 68.92 & $1-2$ years & 10.36 \\
Female & 78 & 31.08 & $3-5$ years & 78 & 31.08 \\
Age & & & $6-10$ years & 78 & 31.08 \\
$<30$ & 55 & 21.91 & $11-20$ years & 53 & 21.12 \\
$31-40$ & 108 & 43.03 & $>20$ years & 16 & 6.36 \\
$41-50$ & 58 & 23.11 & Ownership & & \\
$>50$ & 30 & 11.95 & State-owned & 62 & 24.70 \\
Job title & & & Private & 146 & 58.17 \\
Managing director & 70 & 27.89 & International joint venture & 21 & 8.37 \\
Financial Manager & 38 & 15.14 & Foreign wholly owned & 18 & 7.17 \\
Marketing Manager & 63 & 25.10 & Other & 4 & 1.59 \\
Production Manager & 21 & 8.37 & Firm size (number of employees $)$ & & \\
R\&D Manager & 26 & 10.36 & $<50$ & 45 & 17.93 \\
IT Manager & 8 & 3.19 & $50-199$ & 112 & 44.62 \\
HR Manager & 15 & 5.98 & $200-299$ & 47 & 18.73 \\
Project Manager & 10 & 3.97 & $300-499$ & 17 & 6.77 \\
Education & & & $>500$ & 30 & 11.95 \\
Bachelor's degree & 180 & 71.71 & Sector & & \\
Master's degree & 58 & 23.10 & Manufacturing & 37.85 \\
Doctor's degree & 13 & 51.79 & Service & 156 & 62.15 \\
\hline
\end{tabular}


Table II Scale items and latent variable evaluation

\begin{tabular}{|c|c|}
\hline Construct and items & Weight \\
\hline \multicolumn{2}{|l|}{ Technical KM Infrastructure (TKMI) } \\
\hline \multicolumn{2}{|l|}{ My organization uses } \\
\hline 1. technology that allows employees to collaborate with other persons outside the organisation & 0.13 \\
\hline $\begin{array}{l}\text { 2. technology that allows people in multiple locations to learn as a group from a single source or at a single } \\
\text { point in time }\end{array}$ & 0.29 \\
\hline $\begin{array}{l}\text { 3. technology that allows people in multiple locations to learn as a group from a multiple source or at } \\
\text { multiple points in time }\end{array}$ & 0.09 \\
\hline $\begin{array}{l}\text { 4. technology that allows it to map the location (e.g. an individual, specific system, or database) of specific } \\
\text { types of knowledge }\end{array}$ & 0.86 \\
\hline \multirow{2}{*}{\multicolumn{2}{|c|}{$\begin{array}{l}\text { Social KM Infrastructure (SKMI) } \\
\text { Structural Infrastructure (SI) } \\
\text { My organization ('s) }\end{array}$}} \\
\hline & \\
\hline 1. structure facilitates the discovery of new knowledge & 0.21 \\
\hline 2. structure facilitates the creation of new knowledge & 0.06 \\
\hline 3. bases our performance on knowledge creation & 0.09 \\
\hline 4. has a standardised reward system for sharing knowledge & 0.09 \\
\hline 5. designs processes to facilitate knowledge exchange across functional boundaries & 0.01 \\
\hline 6. managers frequently examine knowledge for errors/mistakes & 0.60 \\
\hline $\begin{array}{l}\text { 7. structure facilitates the transfer of new knowledge across structural boundaries } \\
\text { Culture Infrastructure (CI) }\end{array}$ & 0.23 \\
\hline \multicolumn{2}{|l|}{$\begin{array}{l}\text { Culture Infrastructure (CI) } \\
\text { In my organisation, ... }\end{array}$} \\
\hline 1. employees understand the importance of knowledge to corporate success & 0.41 \\
\hline 2. high levels of participation are expected in capturing and transferring knowledge & 0.24 \\
\hline 3. on-the-job training and learning are valued & 0.29 \\
\hline 4. senior management clearly supports the role of knowledge in our firm's success & 0.34 \\
\hline \multicolumn{2}{|l|}{ People Infrastructure (PI) } \\
\hline \multicolumn{2}{|l|}{ My organisation's members . } \\
\hline 1. can understand not only their own tasks but also others' tasks & 0.14 \\
\hline 2. can make suggestions about others' tasks & 0.14 \\
\hline 3. can communicate well not only with their department members but also with other department members & 0.38 \\
\hline 4. are specialists in their own field of expertise & 0.59 \\
\hline 5. can perform their own task effectively without regard to environmental changes & 0.06 \\
\hline \multicolumn{2}{|l|}{ KM Process Capabilities (KMPC) } \\
\hline \multicolumn{2}{|l|}{ Acquisition Process (AP) } \\
\hline \multicolumn{2}{|l|}{ My organisation ... } \\
\hline 1. has processes for acquiring knowledge about our customers & 0.38 \\
\hline 2. has processes for generating new knowledge from existing knowledge & 0.30 \\
\hline 3. has processes for acquiring knowledge about our suppliers & 0.11 \\
\hline 4. has processes for distributing knowledge throughout the organisation & 0.37 \\
\hline 5. has processes for acquiring knowledge about new products/services within our industry & 0.08 \\
\hline 6. has processes for exchanging knowledge between individuals & 0.44 \\
\hline \multicolumn{2}{|l|}{ Application Process (APP) } \\
\hline \multicolumn{2}{|l|}{ My organisation ... } \\
\hline 1. has processes for using knowledge in development of new products/services & 0.31 \\
\hline 2. has processes for using knowledge to solve new problems & 0.10 \\
\hline 3. matches sources of knowledge to problems and challenges & 0.17 \\
\hline 4. uses knowledge to improve efficiency & 0.03 \\
\hline 5. uses knowledge to adjust strategic direction & 0.21 \\
\hline 6. is able to locate and apply knowledge to changing competitive conditions & 0.13 \\
\hline 7. takes advantage of new knowledge & 0.41 \\
\hline
\end{tabular}


Table II Scale items and latent variable evaluation (continued)

\begin{tabular}{|c|c|}
\hline Construct and items & Weight \\
\hline \multicolumn{2}{|l|}{ Conversion Process $(\mathrm{CP})$} \\
\hline \multicolumn{2}{|l|}{ My organisation .... } \\
\hline 1. has processes for filtering knowledge & 0.33 \\
\hline 2. has processes for transferring organisational knowledge to individuals & 0.25 \\
\hline 3. has processes for absorbing knowledge from individuals into the organisation & 0.25 \\
\hline 4. has processes for integrating different sources and types of knowledge & 0.03 \\
\hline 5. has processes for organising (store/file) knowledge & 0.03 \\
\hline 6. has processes for replacing outdated knowledge & 0.43 \\
\hline \multicolumn{2}{|l|}{ Protection Process (PP) } \\
\hline \multicolumn{2}{|l|}{ My organisation } \\
\hline 1. has processes to protect knowledge from inappropriate use inside the organisation & 0.38 \\
\hline 2. has processes to protect knowledge from inappropriate use outside the organisation & 0.05 \\
\hline 3. has processes to protect knowledge from theft from within the organisation & 0.16 \\
\hline 4. has processes to protect knowledge from theft from outside the organisation & 0.05 \\
\hline 5. has extensive policies and procedures for protecting trade secrets & 0.02 \\
\hline 6. values and protects knowledge embedded in individuals & 0.19 \\
\hline 7. clearly communicates (create awareness of) the importance of protecting knowledge & 0.47 \\
\hline \multicolumn{2}{|l|}{ Competitive Advantage provided by KM (CAPKM) } \\
\hline 1. My organisation often uses knowledge-based innovation & 0.61 \\
\hline 2. My organisation's market position can strong barriers to entry for other firms & 0.03 \\
\hline $\begin{array}{l}\text { 3. My organisation uses knowledge management to widen the array (line/range) of products without } \\
\text { increasing costs }\end{array}$ & 0.31 \\
\hline $\begin{array}{l}\text { 4. The knowledge management capability in my organisation would be difficult and expensive for rivals to } \\
\text { duplicate }\end{array}$ & 0.33 \\
\hline
\end{tabular}

KM - knowledge management; TKMI and CAPKM are formative first-order constructs; SKMI and KMPC are formative first-order, reflective second-order constructs (Type III model) 
Table III Construct means, standard deviations, and correlations

\begin{tabular}{lccccc}
\hline Research constructs & Mean & SD & 1 & 2 & 3 \\
\hline 1. Technical KM Infrastructure (TKMI) & 4.84 & 1.01 & & & \\
2. Social KM Infrastructure (SKMI) & 5.37 & 0.75 & 0.49 & & \\
3. KM Process Capabilities (KMPC) & 5.49 & 0.77 & 0.43 & 0.72 & \\
4. Competitive Advantage provided by KM (CAPKM) & 5.26 & 1.00 & 0.30 & 0.60 & 0.71 \\
\hline
\end{tabular}

Notes: Correlation is significant at the 0.01 level (2-tailed $t$-test). 
Table IV Hypothesis testing

\begin{tabular}{|c|c|c|c|c|c|c|c|}
\hline \multirow{2}{*}{ Dependent variable } & \multirow{2}{*}{ Independent variable } & \multicolumn{3}{|c|}{ Model 1} & \multicolumn{3}{|c|}{ Model 2} \\
\hline & & $\beta$ & $t$-value & $R^{2}$ & $\beta$ & $t$-value & $R^{2}$ \\
\hline \multirow[t]{6}{*}{ CAPKM } & Technical KM Infrastructure & 0.14 & 2.15 & 0.49 & 0.04 & 0.80 & 0.62 \\
\hline & Social KM Infrastructure & 0.62 & 13.12 & - & 0.19 & 2.54 & - \\
\hline & KM Process Capabilities & - & - & - & 0.64 & 7.60 & - \\
\hline & Control & & & & & & \\
\hline & Firm size & 0.03 & 0.65 & - & 0.03 & 0.74 & - \\
\hline & Ownership & 0.08 & 1.82 & - & 0.06 & 1.31 & - \\
\hline \multirow[t]{2}{*}{ KM Process Capabilities } & Technical KM Infrastructure & - & - & - & 0.26 & 4.63 & 0.67 \\
\hline & Social KM Infrastructure & - & - & - & 0.68 & 13.81 & - \\
\hline
\end{tabular}


Table V. fsQCA configurations results

Complex solution

Model: CAPKM = f (TKMI, SKMI, KMPC)

Algorithm: Quine-McCluskey

Frequency cutoff: 30.000000

Consistency cutoff: 0.865672

\begin{tabular}{llll}
\hline & Raw coverage & Unique coverage & Consistency \\
\hline TKMI*SKMI*KMPC & 0.673561 & 0.673561 & 0.865672
\end{tabular}

Solution coverage: 0.673561

Solution consistency: 0.865672

Note: $\mathrm{CAPKM=competitive} \mathrm{advantage} \mathrm{provided} \mathrm{by} \mathrm{KM;} \mathrm{TKMI=} \mathrm{technical} \mathrm{KM} \mathrm{infrastructure;} \mathrm{SKMI=social} \mathrm{KM}$ infrastructure; $\mathrm{KMPC}=\mathrm{KM}$ process capabilities 


\section{REFERENCES}

Alavi, M. and Leidner, D. E. (2001), "Knowledge management and knowledge management systems: Conceptual foundations and research issues", MIS Quarterly Vol. 25 No. 1, pp. 107-36.

Alavi, M. and Tiwana, A. (2005), "Knowledge management: The information technology dimension", in Easterby-Smith M and Lyles M (Eds) The handbook of organisational learning and knowledge management, pp 305-23, Blackwell, Oxford.

Altinay, L., Saunders, M. N., \& Wang, C. L. (2014), "The influence of culture on trust judgments in customer relationship development by ethnic minority small businesses", Journal of Small Business Management, Vol. 52 No. 1, pp. 59-78.

Amit, R., and Schoemaker, P. J. (1993), "Strategic assets and organizational rent", Strategic Management Journal, Vol. 14 No. 1, pp. 33-46.

Andreeva, T. and Kianto, A. (2012), "Does knowledge management really matter? Linking knowledge management practices, competitiveness and economic performance", Journal of Knowledge Management, Vol. 16, No. 4, pp. 617-636.

Appleyard, M. (1996), "How does knowledge flow? Interfirm patterns in the semiconductor industry", Strategic Management Journal Vol. 17 (Winter), pp. 137-54.

Ashrafi, R. and Mueller, J. (2015), "Delineating IT resources and capabilities to obtain competitive advantage and improve firm performance", Information Systems Management, Vol. 32 No. 1, pp. 15-38.

Barney, J. (1991), "Firm resources and sustained competitive advantage", Journal of Management, Vol.17 No. 1, pp. 99-120.

Bharadwaj, A. S. (2000), "A resource-based perspective on information technology capability and firm performance: an empirical investigation” MIS Quarterly, Vol. 24 No. 1, pp. 169196.

Bhatt, G. D. (2001), "Knowledge management in organizations: examining the interaction between technologies, techniques, and people", Journal of Knowledge Management, Vol. 5 No. 1 , pp. 68-75.

Brislin, R. W., Lonner, W. J., and Thorndike, R. M. (1973), Cross-Cultural: Research Methods, Vol. 11. Year Book Medical Pub.

Buettgen, A., Richardson, J., Beckham, K., Richardson, K., Ward, M., \& Riemer, M. (2012). We did it together: A participatory action research study on poverty and disability. Disability \& Society, 27(5), 603-616. 
Byrd, T. A., Lewis, B. R. and Turner, D. E. (2005), "The impact of IT personnel skills on IS infrastructure and competitive IS", Advanced Topics in Information Resources Management, Vol 5, p. 63.

Byrd, T. A., \& Turner, D. E. (2001a), "An exploratory analysis of the value of the skills of IT personnel: Their relationship to IS infrastructure and competitive advantage", Decision Sciences, Vol 32 No. 1, pp. 21-54.

Byrd T. A. and Turner, D. E. (2001b), "An exploratory examination of the relationship between flexible IT infrastructure and competitive advantage", Information and Management, Vol. 39, pp. 41-52.

Laszlo, C. K., \& Laszlo, A. (2002). Evolving knowledge for development: the role of knowledge management in a changing world. Journal of Knowledge Management, 6(4), 400-412.

Chakravarthy, B., McEvily, S., Doz, Y. and Rau D. (2005), "Knowledge management and competitive advantage", in Esterby-Smith M. and Lyles M. (Eds), The handbook of organisational learning and knowledge management, pp. 305-23, Blackwell, Oxford.

Child, J., \& Tse, D. K. (2001). "China's transition and its implications for international business". Journal of International Business Studies, Vol. 32 No. 1, pp. 5-21.

Choi, B. and Lee, H. (2002), "Knowledge management strategy and its link to knowledge creation process", Expert Systems with Applications, Vol. 23 No. 3, pp. 173-87.

Choi, B. and Lee, H. (2003), "An empirical investigation of knowledge management styles and their effect on corporate performance", Information and Management, Vol. 40, pp. 40317.

Chuang, S. H. (2004), "A resource-based perspective on knowledge management capability and competitive advantage: An empirical investigation”, Expert Systems with Applications, Vol. 27, pp. 459-65.

Clemons, E. and Row, M. (1991), "Sustaining information technology advantage: The role of structural differences”, MIS Quarterly, September, pp. 275-92.

Conner, K. R. (1991), “A historical comparison of resource-based theory and five schools of thought within industrial organization economics: do we have a new theory of the firm?", Journal of Management, Vol. 17 No. 1, pp. 121-154.

Cooper, R. B. and Zmud, R. W. (1990), "Information technology implementation research: A technological diffusion approach", Management Science, Vol. 36 No. 2, pp. 123-39.

Davenport, T. H. and Prusak, L. (1998), Working knowledge: How organisations manage what they know, Havard Business School Press, Boston. 
Dierickx, I., \& Cool, K. (1989), "Asset stock accumulation and sustainability of competitive advantage", Management science, Vol 35 No 12, pp. 1504-1511.

Duffy, S., Northey, G., \& van Esch, P. (2017). Iceland: how social mechanisms drove the financial collapse and why it's a wicked problem. Journal of Social Marketing, 7(3).

Eisenhardt, K. M. and Martin, J. A. (2000), "Dynamic capabilities: What are they?", Strategic Management Journal, Vol. 21 No. 10/11, pp. 1105-22.

Ergazakis, K., Metaxiotis, K., \& Psarras, J. (2004). Towards knowledge cities: conceptual analysis and success stories. Journal of Knowledge Management, 8(5), 5-15.

Fichman, R. G. and Kemerer, C. F. (1997), "The assimilation of software process innovations: An organisational learning perspective", Management Science, Vol. 43 No. 10, pp. 134563.

Fiss, P. C. (2011), "Building better causal theories: A fuzzy set approach to typologies in organization research", Academy of Management Journal, Vol. 54 No. 2, pp. 393-420.

Gimenez A. O. and Rincon, M. (2003), Knowledge management in the developing countries: An empirical approach in search of limitations and opportunities, Proceedings of the Fourth European Conference on Knowledge Management, 18-19 September, Oxford, England.

Gold, A. H., Malhotra, A. and Segars, A. H. (2001), "Knowledge management: An organisational capabilities perspective”, Journal of Management Information Systems, Vol. 18 No. 1, pp. 185-214.

Granados, M. L., Granados, M. L., Mohamed, S., Mohamed, S., Hlupic, V., \& Hlupic, V. (2017), "Knowledge management activities in social enterprises: lessons for small and non-profit firms", Journal of Knowledge Management, Vol. 21 No. 2, pp. 376-396.

Grant, R. M. (1996), “Toward a knowledge-based theory of the firm”, Strategic Management Journal, Vol. 17, pp. 109-22.

Grant, R. M. (1991), "The resource-based theory of competitive advantage: implications for strategy formulation", California Management Review, Vol. 33 No. 3, pp. 114-135.

Gu, Q., Jitpaipoon, T., \& Yang, J. (2017), "The impact of information integration on financial performance: A knowledge-based view”, International Journal of Production Economics.

Hair J. F.., Sarstedt, M., Hopkins, L. and Kuppelwieser, G. V. (2014), "Partial least squares structural equation modelling (PLS-SEM) An emerging tool in business research", European Business Review, Vol 26 No. 2, pp. 106-121.

Hair, J. F., Black, WC, Babin, BJ, \& Anderson, RE (2010), Multivariate data analysis, 7.

Hair J. F., Black, W. C., Babin, B. J., Anderson, R. E. and Tatham, R. L. (2006), Multivariate data analysis, Pearson Education International, New Jersey. 
Hamel, G. and Prahalad, C. K. (1996), Competing for the future, Harvard Business School Press, Boston.

Hamel, G., \& Prahalad, C. K. (1996), "Research Notes and Communications: Competing in the New Economy: Managing Out of Bounds", Strategic Management Journal, Vol. 17, pp. 237-242.

Hansen, M. T. (1999), "The search-transfer problem: The role of weak ties in sharing knowledge across organisation subunits", Administrative Science Quarterly Vol. 44, pp. 82-111.

Hayes, A. F., Montoya, A. K., and Rockwood, N. J. (2017), "The analysis of mechanisms and their contingencies: PROCESS versus structural equation modelling", Australasian Marketing Journal, Vol. 25 No. 1, pp. 76-81.

Hayes, A. F. (2013), Introduction to mediation, moderation, and conditional process analysis: A regression-based approach. Guilford Press.

He, W., \& Wei, K.-K. (2009), What drives continued knowledge sharing? An investigation of knowledge-contribution and-seeking beliefs. Decision Support Systems, 46(4), 826-838.

Hedlund, G., \& Nonaka, I. (1993), Models of knowledge management in the west and Japan. In P. Lorange, B. Chakravarthy, J. Roos, \& A. Van de Ven (Eds.), Implementing Strategic ProcessesChange, Learning, and Co-Operation (pp. 117-144). Oxford, UK.: Blackwell.

Henderson, J. and Venkatraman, N. (1993), "Strategic alignment: Leveraging information technology for transforming organisations", IBM Systems Journal, Vol. 32, pp. 4-16.

Hult, G. T. M., Ketchen, D. J., Cavusgil, S. T., \& Calantone, R. J. (2006). Knowledge as a strategic resource in supply chains. Journal of operations management, 24(5), 458-475.

Inkpen, A. (1996), “Creating knowledge through collaboration”, California Management Review, Vol. 39 No. 1, pp. 123-41.

Ketchen, D. J., Hult, G. T. M., and Slater, S. F. (2007). Toward greater understanding of market orientation and the resource-based view. Strategic Management Journal, Vol 28 No 9, pp. 961-964.

Khalifa, M., Lam, R. and Lee, M. (2001), An integrative framework for knowledge management effectiveness. Proceedings of the Twenty-Second Conference on Information Systems, September, New Orleans.

Khalifa, M. and Liu, V. (2003), Knowledge management effectiveness. Proceedings of the Fourth European Conference on Knowledge Management, 18-19 September, Oxford, England.

Kline, R. B. (2005), Principles and practice of structural equation modeling, Guilford Press, New York. 
Kotha, S. (1995), "Mass customization: implementing the emerging paradigm for competitive advantage", Strategic Management Journal, Vol 16 No S1, pp. 21-42.

Lee, H. and Choi, B. (2003), "Knowledge management enablers, processes, and organisational performance: An integrative view and empirical examination", Journal of Management Information Systems, Vol. 20 No. 1, pp 179-228.

Leonard-Barton, D. (1995), "Wellsprings of knowledge: Building and sustaining the sources of innovation", University of Illinois at Urbana-Champaign's Academy for Entrepreneurial Leadership Historical Research Reference in Entrepreneurship.

Lindell, M. K., and Whitney, D. J. (2001), "Accounting for common method variance in crosssectional research designs" Journal of Applied Psychology, Vol. 86 No. 1, p. 114.

Lopez, S. V. (2005), "Competitive advantage and strategy formulation: The key role of dynamic capabilities", Management Decision, Vol. 43 No. 5, pp. 661-9.

Mageswari, U. S. D., Sivasubramanian, R. C., and Dath, T. S. (2017), "A comprehensive analysis of knowledge management in Indian manufacturing companies", Journal of Manufacturing Technology Management, Vol. 28 No. 4, pp 506-530.

Meschi, P. X., Phan, T. T., and Wassmer, U. (2016). "Transactional and institutional alignment of entry modes in transition economies. A survival analysis of joint ventures and wholly owned subsidiaries in Vietnam”. International Business Review, Vol. 25 No. 4, pp. 946959.

McDermott, R. and O'Dell, C. (2001), "Overcoming cultural barriers to sharing knowledge", Journal of Knowledge Management, Vol. 5 No. 1, pp. 76-85.

Migdadi, M. M. (2005), "An integrative view and empirical examination of the relationships among knowledge management enablers, processes, and organisational performance in Australian enterprises", Published doctoral thesis, University of Wollongong, Australia.

Mills, A. M., and Smith, T. A. (2011), "Knowledge management and organizational performance: a decomposed view", Journal of Knowledge Management, Vol. 15 No. 1, pp. 156-171.

Nahapiet, J. and Ghoshal, S. (1998), "Social capital, intellectual capital, and the organisational advantage", Academy of Management Review, Vol. 23 No. 2, pp. 242-66.

Nguyen, Q. and Neck, P. (2008), Key enablers for enhancing knowledge management processes: A means of competitive advantage for small and medium sized enterprises in Vietnam. Proceedings of the 2008 Entrepreneurship Global Conference, 3-4 July, Melbourne, Australia. 
Nielsen, A. P. (2006), "Understanding dynamic capabilities through knowledge management", Journal of Knowledge Management Vol. 10 No. 4, pp. 59-71.

O'Cass, A., \& Ngo, L.V. (2007). Market orientation versus innovative culture: two routes to superior brand performance. European Journal of Marketing, 41(7/8), 868-887.

Pentland, B. T. (1995), "Information systems and organizational learning: the social epistemology of organizational knowledge systems", Accounting, Management and Information Technologies, Vol. 5 No. 1, pp. 1-21.

Peteraf, M. A. (1993). The cornerstones of competitive advantage: A resource-based view. Strategic Management Journal, 14(3), 179-191.

Petrescu, M. (2013). Marketing research using single-item indicators in structural equation models. Journal of Marketing Analytics, 1(2), 99-117.

Podsakoff, P. M., MacKenzie, S. B., Lee, J. Y. and Podsakoff, N. P. (2003), "Common method biases in behavioral research: a critical review of the literature and recommended remedies", Journal of Applied Psychology, Vol. 88 No. 5, p. 879.

Porter, M. E., \& Millar, V. E. (1985). How information gives you competitive advantage. Harvard Business Review, 85(Jul-Aug), 149-160.

Powell, T. C. and Dent-Micallef, A. (1997), "Information technology as competitive advantage: The role of human, business, and technology resources", Strategic Management Journal, Vol. 18 No. 5, pp. 375-405.

Powell, W. W. and Snellman, K. (2004), "The knowledge economy", Annual Review of Sociology, Vol. 30, pp. 199-220.

Preacher, K. J. and Hayes, A. F. (2008), "Assessing mediation in communication research", The Sage sourcebook of advanced data analysis methods for communication research, pp. 1354.

Ragin, C. C. (2008), Redesigning social inquiry: Fuzzy sets and beyond(Vol. 240). Chicago: University of Chicago Press.

Ringle, C. M., Wende, S. and Becker, J. M. (2015), SmartPLS 3.Boenningstedt: SmartPLS GmbH, http://www. smartpls. com.

Ross, J. W., Beath, C. M. and Goodhue, D. L. (1996), "Develop long-term competitiveness through IT assets", Sloan Management Review, Vol. 38 No. 1, pp. 31-42.

Rubenstein-Montano, B., Liebowitz, J., Buchwalter, J., McCaw, D., Newman, B., Rebeck, K., \& Team, T. K. M. M. (2001). A systems thinking framework for knowledge management. Decision Support Systems, 31(1), 5-16. 
Smith, T. A. (2006), "Knowledge management and its capabilities linked to the business strategy for organisational effectiveness" Published doctoral thesis, Nova Southeastern University, USA.

Szulanski, G. (1996), "Exploring internal stickiness: Impediments to the transfer of best practice within the firm", Strategic Management Journal Vol. 17 (Winter), pp. 27-43.

Tanriverdi, H. (2005), "Information technology relatedness, knowledge management capability, and performance of multibusiness firms", MIS Quarterly, Vol. 29 No. 2, pp. 311-334.

Tseng, S. M. (2016),"The effect of knowledge management capability and customer knowledge gaps on corporate performance", Journal of Enterprise Information Management, Vol. 29 No. 1, pp. 51-71.

Tseng, S. M. (2010), "The correlation between organizational culture and knowledge conversion on corporate performance" Journal of Knowledge Management, Vol. 14 No. 2, pp. 269284.

Nguyen, T.M., N. T., Jung, K., Lantz, G., \& Loeb, S. G. (2003). An exploratory investigation into impulse buying behavior in a transitional economy: A study of urban consumers in Vietnam. Journal of International Marketing, 11(2), 13-35.

United Nations. (2016). World Economic Situation and Prospects. New York: United Nations, Retrieved from www.un.org/en/development/desa/policy/wesp/

Van Den Hooff, B., Schouten, A. P., and Simonovski, S. (2012). "What one feels and what one knows: the influence of emotions on attitudes and intentions towards knowledge sharing", Journal of Knowledge Management, Vol. 16 No. 1, pp. 148-158.

Vu, V., H., Tran, T. Q., Van Nguyen, T., \& Lim, S. (2016). Corruption, types of corruption and firm financial performance: New evidence from a transitional economy. Journal of Business Ethics, 1-12. 
Verona, G. and Ravasi, D. (2003), "Unbundling dynamic capabilities: An exploratory study of continuous product innovation", Industrial and Corporate Change Vol. 12 No. 3, pp. 577606.

Winter, S. G. (2003), "Understanding dynamic capabilities”, Strategic Management Journal Vol. 24 No. 10, pp. 991-5.

Woodside, A. G. (2013), "Moving beyond multiple regression analysis to algorithms: Calling for adoption of a paradigm shift from symmetric to asymmetric thinking in data analysis and crafting theory", Journal of Business Research, Vol. 66 No. 4, pp. 463-472.

Wu, I. L., and Chen, J. L. (2014), "Knowledge management driven firm performance: The roles of business process capabilities and organizational learning", Journal of Knowledge Management, Vol. 18 No. 6, pp. 1141-1164.

Zack, M. H. (1999), "Developing a knowledge strategy”, California Management Review Vol. 41 No. 3, p 125.

Zack, M., McKeen, J., and Singh, S. (2009), "Knowledge management and organizational performance: an exploratory analysis", Journal of Knowledge Management, Vol. 13 No. 6, pp.392-409.

Zaim, H., Tatoglu, E., and Zaim, S. (2007), "Performance of knowledge management practices: a causal analysis", Journal of Knowledge Management, Vol 11 No. 6, pp. 54-67.

Zander, D. and Kogut, B. (1995), "Knowledge and the speed of the transfer and imitation of organisational capabilities: An empirical test", Organisation Science Vol. 6 No. 1, pp. 7692.

Zheng, W. (2005), "The impact of organisational culture, structure, and strategy on knowledge management effectiveness and organisational effectiveness". Published doctoral thesis, University of Minnesota, USA.

Zheng, W., Yang, B. and McLean, G. N. (2010), "Linking organizational culture, structure, strategy, and organizational effectiveness: Mediating role of knowledge management", Journal of Business Research, Vol. 63 No. 7, pp. 763-771.

Zhou, W. (2017). Institutional environment, public-private hybrid forms, and entrepreneurial reinvestment in a transition economy. Journal of Business Venturing, 32(2), 197-214. 